\title{
Imaginando los ríos ${ }^{* 1}$
}

\author{
Kuntala Lahiri-Dutt ${ }^{* *}$ \\ Australian National University, Australia
}

DOI: https://doi.org/10.22380/2539472X.574

Los seres humanos a menudo han personificado a los ríos. Pero el paso de un río "madre" naturaleza a un río "hija obediente" ha sido perjudicial para el bienestar humano. Necesitamos ver a los ríos como un [lugar] en el que vivimos, y no como un recurso que “aprovechamos” y "controlamos".

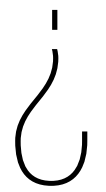

Qué es un río? ¿Es solo lo que imaginamos que es? Los ríos existen, son "entidades incorporadas" que se pueden ver, sentir, tocar y rastrear en un mapa. Sus características - diferentes y visibles como sin duda lo son y lo han sido-se experimentan en un cuerpo físico. Todavía tenemos una plétora de imágenes y diferentes discursos de “el río” que reflejan una confusión sobre qué es el río, qué debería ser y qué debe hacerse si, como un "recurso", queremos obtener lo mejor del agua que lleva. Por lo tanto, es posible ver los ríos de diferentes maneras, lo que da cuenta de su construcción social e histórica. Como estudiante de geografía que cruza los mundos físico y social, he seguido con mucho interés las emociones en torno al río Narmada, así como el tema de la planificación de los recursos hídricos en la India, y me he preguntado si existe una forma correcta de imaginar los ríos. No intento corregir o complementar una representación falsa o incompleta, pues

\footnotetext{
* $\quad$ "Imagining Rivers" fue publicado originalmente en la edición 35-27 de Economic and Political Weekly, en el 2000. El ICANH agradece a la autora y a la revista original la autorización de su traducción y reimpresión para el dosier especial de la RCA sobre antropologías del agua.

** Kuntala Lahiri-Dutt es geógrafa humana, profesora e investigadora en el Resource, Environment and Development Program de la Crawford School of Public Policy de la Australian National University. Es experta mundial en investigación crítica sobre género y comunidad en temas de agua e industrias extractivas (minería). Sus investigaciones se han enfocado en Asia y se han basado en metodologías de investigación académicas y activistas feministas. $\mathrm{Su}$ trabajo específico en el campo del agua ha criticado de forma innovadora las visiones convencionales y dominantes sobre los ríos, las relaciones agua-tierra y agua-minería, el agua en el hogar y las intersecciones entre agua y género.
}

1 Reconozco la deuda inmensa que tengo con las discusiones que mantuve con Ramaswamy Iyer, Gail Omvedt, Deepak Giwali, Ajaya Dikshit, Jayanta Bandyopadhyay y Katherine Gibson durante la escritura de este artículo. 
puede que no exista una forma ideal y correcta de representar los ríos. El foco de mi discusión es cómo se han conceptualizado los ríos y cómo la agenda de modernización y desarrollo del gobierno ha creado oposiciones binarias, como tradicional versus desarrollista, antirrepresa versus prorrepresa, local versus global, biocéntrico versus antropocéntrico y pequeño versus grande.

Comenzaré con un ejemplo. En su artículo "El problema de la excavación de canales en Damodar Valley Corporation”, publicado en 1959 en el Indian Journal of Power and River Valley Development, Ram Sarup, un ingeniero de Damodar Valley Corporation (DVC), describió cómo el trabajo de construcción de canales avanzó en medio de grandes problemas, y cómo fueron enfrentados. Sarup explicó cómo llevaron grandes bulldozers para "limpiar la tierra”, ya que las espesas junglas y las lagunas obstaculizaban el estudio del área. Luego se usaron "bombas pesadas" para "desaguar" las lagunas, y las lomas entre las lagunas fueron "erradicadas” para "evitar daños a los neumáticos”. De esta manera, el suelo aluvial, blando y deltaico se endureció para que los tractores raspadores pudieran ser utilizados. Dado que el nivel freático era muy alto, "las canteras se dejaron secar por varios días y las máquinas tuvieron que llenar los terraplenes por partes, aquí y allá, en lugares adyacentes a su respectiva área de banco de préstamo de materiales”. Aun así, el uso de máquinas resultó difícil ya que los tractores raspadores se atascaron y "tuvieron que ser remolcados con gran dificultad”. Luego surgió un problema de escasez de suelo mientras se construían los terraplenes a lo largo del Damodar, y "se adquirió un poco más de tierra para satisfacer la necesidad de suelo". Sin embargo, los terraplenes a su vez crearon otro problema, pues obstruyeron los afluentes que desembocan en el Damodar y los distributarios que se desprenden de él. Así, el río Sali "se cerró al construirse los terraplenes a lo largo del curso del río principal”. La perspectiva de Ram Sarup debió haber sido la manera "correcta” de imaginar los ríos en una India que aspiraba a capturar los beneficios de la tecnología y la ciencia occidental.

Ram Sarup escribió su artículo hace cuarenta años, en un momento en el que los efectos ambientales y ecológicos del desarrollo no recibían la atención adecuada en el mundo. Pero, aun así, parece como si todo esto sucediera en el vacío, en un espacio creado por primera vez por la ciencia y la tecnología modernas y para ser moldeado por estas mismas fuerzas. Como si de repente el agua que fluye por el río se convirtiera en un "recurso", y como si cualquier exceso (o falta de ella) se convirtiera en una restricción. Cuando el agua de un río desembocaba en el mar, esta era vista como un "desperdicio". El "recurso", tal y como se veía, debía usarse de cierta manera por primera vez como si nadie hubiera vivido en la tierra ni utilizara el agua anteriormente. Como si el río no tuviera un pasado 
consciente; fue tratado solo como una figura en un paisaje, más que como una imagen relacionada con el tiempo y el lugar. Este es un tipo de "espacio newtoniano", basado en los movimientos predecibles y organizados de los objetos sobre un espacio no diferenciado que se hizo visible por primera vez. En este espacio, el río es solo una "cosa" que puede modificarse, controlarse y dársele forma según los deseos humanos, mediante el uso de técnicas y conocimientos científicos "superiores". Esta visión de los ríos cree en la durabilidad, la estabilidad y la continuidad, y cree que la ciencia moderna por sí sola puede dar una interpretación consistente y sistemática de todos los fenómenos que vemos a nuestro alrededor.

El artículo de Ram Sarup también nos dice de manera sobresaliente, aunque indirecta, algo sobre la orientación ideológica del desarrollo en el Estado poscolonial, así como sobre la economía política de la planificación de los recursos hídricos en la India. Nos dice de qué modo se representaron los ríos en la perspectiva "oficial" hace cuarenta años, cuando el DVC construyó las represas y los terraplenes en un intento por "controlar" el río. Si el ambiente natural es una construcción social, entonces esa sociedad debe situarse desde la perspectiva de su tiempo y su lugar. A través de la representación de los ríos de una cierta manera, el Estado también genera una representación de sí mismo como un controlador de todos los elementos del entorno natural y se dota de un poder performativo en términos del control de los ríos.

Afirmaciones como "las inundaciones causan enorme sufrimiento humano y pérdidas económicas" abundan en los documentos de gobierno, tanto en el pasado como en el presente. Cuando un río se inunda es visto como una "amenaza”, y se supone que el Estado tiene la responsabilidad de remediar esa situación. Los medios de comunicación urbanos también perciben las inundaciones como un "desastre". Las inundaciones en el este de India y Bangladesh atraen mucha atención de los medios nacionales e internacionales. Debido a que crean buenas historias sobre la miseria humana, los medios resaltan el ángulo del "desastre” ya que no cuentan con la información disponible sobre las causas de las inundaciones. La cadena de eventos que sigue a una "inundación" — que la representa como un comportamiento aberrante de los ríos-invariablemente conduce a un consenso de alto nivel sobre la necesidad de algún tipo de control del río. Probablemente esto se deba a que la noción de "comportamiento pervertido" del río hace que uno se sienta incómodo y nos recuerda nuestro propio pantano de irracionalidad, y por lo tanto nos invita a intentar controlar tal comportamiento. Términos como domar y amansar el río se utilizan con frecuencia en la literatura creciente sobre gestión de los recursos hídricos. Hay una arrogancia inherente al usar una metáfora ecuestre para un río, o al tratar de "domar” un río salvaje 
"amansándolo". Como si los ríos imaginados fueran incivilizados y tuvieran que ser controlados mediante la creación de algo de gran belleza y magnificencia.

El uso de estos términos para describir el comportamiento de los ríos explica por qué el recientemente independizado Estado de India asumió los derechos de control de los ríos. Esto se hizo prácticamente de la misma manera adoptada en los países desarrollados de Occidente. Al imponer en los ríos de la India oriental un modelo estructural de control fluvial desarrollado en América ${ }^{2}$, el Estado hizo una declaración de su creencia en la aplicación de principios universales y a la vez negó la singularidad de nuestros ríos. De igual manera, este modelo privó a las comunidades locales que viven en las áreas ribereñas de sus derechos de administrar sus propios recursos en formas que han demostrado ser efectivas a lo largo del tiempo. Sobre todo, las soluciones técnicas adoptadas para "controlar" los ríos restringieron los derechos de los ríos a moverse por el espacio, y esto no solo dio lugar a una serie de problemas técnicos sino también a inmensos problemas políticos. Por lo tanto, lo que el río y sus cambiantes estados de ánimo significaron para aquellos que vivían en su cuenca, y para quienes tomaron decisiones tecnológicas por ellos, debe ser entendido en primera instancia. A través de este entendimiento, podemos examinar el conocimiento que subyace a la tecnología adoptada por el Estado. Podemos entender también los procesos políticos, sociales y económicos que condujeron a la adopción de la tecnología de grandes represas y terraplenes a lo largo de cursos fluviales. ¿Qué verdaderas "necesidades objetivas" subyacen a la selección de esta tecnología? ¿Esta tecnología dio lugar a un avance del conocimiento humano desarrollado en las llanuras inundables durante cientos de años? ¿O fue esto un producto de la manera como los ríos y sus inundaciones tenían unos significados fijados por la élite occidental urbana y educada con acceso al poder de tomar decisiones? Dado que los ríos son el elemento natural más crítico en la Bengala deltaica, ¿se consideraron la pluralidad y la heterogeneidad de opciones antes de tratar los ríos de una manera específica?

Las relaciones de poder envuelven nuestras vidas en diferentes niveles. Dominar es un objetivo popular que por mucho tiempo ha sido visto como una preocupación principal de los humanos. El río no está fuera de la sociedad, ni es simplemente una cosa en la naturaleza. Por el contrario, los ríos interactúan constantemente con la cultura, de tal manera que la forma como se tratan está ampliamente determinada por una maraña de relaciones y narrativas que afectan al río y con las que este está constantemente negociando e incluso resistiendo. 
Las definiciones de "ríos" se componen de discursos y narrativas que a su vez afectan las políticas y el comportamiento, y se implementan de manera tal que afectan directamente al cuerpo del río. Gran parte de la controversia sobre el “río” en los tiempos contemporáneos surge porque los símbolos se confunden con la memoria, y la memoria y los símbolos, con los ríos propiamente dichos. Por lo tanto, nuestra idea de "río" se basa en una noción simplificada, un mito que puede verse como el resultado de desarrollos históricos convergentes de ideas, discursos, legislación y de nuestros propios procesos psicológicos de memoria y proyección. El mito está vivo y ha sido creído; nos dice que los ríos son objetos que tienen valor para nosotros como recursos, y que cualquier comportamiento discordante de su parte debe frenarse. Nosotros, como ciudadanos, hemos contribuido fuertemente a la perpetuación del mito porque, si no lo hiciéramos, nuestras propias ideas precarias sobre el control de la naturaleza estarían en peligro, y eso puede sacudir las raíces de nuestro propio sentido de nosotros mismos y de nuestra identidad. Por lo tanto, luchamos para proteger la dependencia del río y proyectamos lo que vemos como su comportamiento “correcto” y “apropiado”. Esto nos otorga un alto grado de poder y control sobre los ríos. Sin saberlo, estamos usando "el río” como un símbolo, confundiéndolo una vez más con los ríos reales y con lo que representa el río para diferentes personas en diferentes contextos.

Obviamente, los ríos no existen en un vacío excepto en la visión de Ram Sarup. Los ríos no están separados del resto de la sociedad y la cultura, aunque el mito dice que en realidad lo están y deberían estarlo. Tal mito fue construido históricamente por las clases medias urbanas indias que estuvieron expuestas al pensamiento científico occidental y fue, en gran medida, impuesto sobre nuestros ríos mediante la separación de las comunidades locales de sus derechos al manejo del agua de los ríos, y sobre otros a través de medidas como la educación universal. Crecemos creyendo lo que nos enseñaron en nuestra escuela y en nuestros libros de texto, que todos los ríos fluyen y pueden hacerlo de una manera controlada. Crecemos leyendo y viendo en documentales el éxito de DVC con sus impresionantes represas de concreto derramando agua en los canales.

Los ríos y sus inundaciones, tal como han sido creados socialmente en la India poscolonial, revelan cómo los conceptos occidentales pueden trasplantarse completamente a un contexto totalmente diferente. En el contexto del "desarrollo" fluvial, este conocimiento fue visto como autónomo y objetivo, "valores” como la razón y la racionalidad se han construido como "buenos” y concomitantes con el "desarrollo”. Esta visión del mundo revela una arrogancia tóxica por parte de los humanos armados con conocimiento y tecnología “científica”, tomada de los gobernantes imperiales. ¿Cuáles son las características fundamentales 
de este conocimiento? Su universalismo, su imagen de la naturaleza como un adversario, su supuesto de replicabilidad y su agenda de "marcha del progreso". En otras palabras, la suposición es que lo que es aplicable en Occidente funcionaría perfectamente en la India (o en cualquier otro lugar) y que eso "elevaría el nivel de vida de las personas" (otra expresión de uso frecuente).

Como resultado, los planificadores de los recursos hídricos no valoraron las diferencias entre los ríos europeos/americanos y los de la India, particularmente la singularidad de los contextos socionaturales de estos últimos. Estos ríos tienen variaciones estacionales significativas en su flujo, drenan áreas densamente pobladas e intensamente cultivadas, no tienen cursos estables y, sobre todo, desplazan enormes cantidades de sólidos con sus aguas durante los monzones. La furia de los ríos durante la temporada de lluvias y el miedo resultante han propagado un "síndrome de desastre" en la ciencia de los ríos. Este miedo concibe las inundaciones como un comportamiento desviado de los ríos, algo que no es normal, que interfiere con el bienestar de las personas que viven en las llanuras de inundación. Los expertos urbanos formaron "comités de investigación" y convocaron a científicos y tecnócratas occidentales, que finalmente entregaron al Estado la responsabilidad de vigilar los ríos de la forma elegida por ellos. Así, la "mitigación de las inundaciones" se convirtió en una parte de la forma como se vende el sueño fantástico de los proyectos multipropósito en los valles de los ríos de la India, un mito simplificado que ahora enfrenta severas críticas después de la experiencia con estos proyectos en las últimas dos décadas. Los diversos "propósitos” delineados en proyectos ribereños revelan conflictos sistémicos entre sí: "aumentar el flujo en temporada de escasez" no concuerda con la generación hidroeléctrica, y el "control de inundaciones” entra en conflicto con el almacenamiento de agua en los embalses, los cuales deben mantenerse vacíos para poder almacenar el exceso de agua de los monzones.

¿Cómo cumplió el Estado la obligación de vigilar los ríos? El Estado estableció múltiples instituciones y agencias para el control de las inundaciones, para el riego y para la rehabilitación de las personas desplazadas en los proyectos ribereños. Estos proyectos representan un enfoque fragmentario al tratar con una sola entidad como un río. Cuando ocurren inundaciones a pesar de todas las intervenciones tecnológicas e institucionales para prevenirlas, inevitablemente hay una respuesta de emergencia por parte del Estado. No es de extrañar que no haya una única agencia para hacer frente a las consecuencias de las inundaciones. Esta parte crítica, que influye directamente en el bienestar y la seguridad de las comunidades humanas, supuestamente no es responsabilidad de nadie. Por lo tanto, los conflictos de intereses dentro del gobierno, así como el consiguiente 
sentido de culpabilidad, están detrás de la provisión de asistencia durante las inundaciones. En la mayoría de las situaciones posinundación, el fracaso institucional ha sido impactante. Año tras año, uno es testigo del espectáculo de la política de asistencia durante las inundaciones e, inevitablemente, el furor se desvanece en un par de meses. Las inundaciones tienen una dimensión de seguridad humana, aunque casi siempre se han visto desde un ángulo técnico. Las verdaderas víctimas de una inundación generalmente se eligen por clase, pues en la mayoría de los casos los pobres se ven más afectados. Una gran inundación puede volver a los pobres más vulnerables, marginarlos aún más, e incluso desarraigarlos de sus tierras. La preocupación del Estado por la tecnología de prevención de inundaciones que él mismo adopta se entiende muy bien por la falta de un programa de seguro contra inundaciones bien concebido, infalible, popular y bien publicitado para las personas pobres que viven en los entornos marginales de las áreas propensas a las inundaciones.

Cuando hay una inundación, como sucedió el año antepasado³ se hacen varias conjeturas. Tomemos la inundación de 1998 en Bengala, por ejemplo. ¿Fue por un clima anormal, relacionado con la ocurrencia de El Niño, causado por la deforestación en el Himalaya? ¿Por un terremoto submarino y el movimiento de placas en la bahía de Bengala, una pobre atención al problema de las inundaciones o una combinación de estos factores? ¿O fue solo otra inundación en una región propensa a las inundaciones? Después de varios seminarios y reuniones, aún no hemos llegado a una conclusión definitiva que ponga toda la responsabilidad en algún factor u otro. Sin embargo, las inundaciones no son inusuales en el Bengala deltaico. La tierra misma ha sido construida durante miles de años con sedimentos traídos por el Ganga Brahmaputra-Meghannad y sus innumerables tributarios y distributarios. Una de las principales causas de las inundaciones es que los ríos descienden rápidamente desde las tierras altas llevando enormes cantidades de limo a la tierra plana. Las aguas sobrantes alcanzan la llanura durante las lluvias donde encuentran los tramos bajos de los ríos ya llenos, e invariablemente causan inundaciones generalizadas en los meses del monzón. Además, la región actúa como un embudo para drenar las aguas de todo Nepal, las llanuras del Ganges, las cordilleras Sikkim y Darjeeling y las colinas nororientales de los Himalayas. Los estuarios del delta de Bengala se encuentran en una región de mareas activas, lo que dificulta la salida de agua del río durante la marea alta. Finalmente, si las descargas máximas de los sistemas del Ganga y el Brahmaputra ocurren simultáneamente, las inundaciones están destinadas 
a ocurrir. Por lo tanto, las inundaciones no solo son inevitables, sino que también son una característica inherente al proceso mediante el cual se formó la tierra en esta llanura deltaica durante miles de años.

Las prácticas de “entrenamiento fluvial” adoptadas por el Estado también han ignorado que durante los monzones los ríos no solo transportan agua. Los ríos reubican enormes cantidades de sedimentos desde la región altamente erosionable del Himalaya hasta las llanuras de inundación. De hecho, en promedio alrededor del 50\% del agua que desciende de los Himalayas de Nepal durante la temporada de lluvias está compuesta de sólidos de varios tamaños. El control estructural de las presas en las zonas montañosas, diseñadas para evitar que el flujo de las tierras altas llegue a los ríos crecidos de las llanuras, o los altos terraplenes a lo largo del río, vistos como "el único remedio práctico” para las inundaciones, nunca ha abordado adecuadamente la cuestión de los sólidos en las aguas de los ríos. ¿Adónde irán esos sólidos? ¿Se acumularán en los embalses, en los canales o en los campos cultivados cuando haya una brecha en el terraplén? ¿Cuál es la naturaleza de los sólidos? ¿Son arena, limo o arcilla? Sin embargo, los sistemas de acomodación humana a las inundaciones que se han dado a lo largo de los siglos reconocieron e incluso aceptaron el hecho de que los sólidos se mezclan con los flujos monzónicos de los ríos. William Willcocks escribió, en su ensayo seminal “Ancient Systems of Irrigation in Bengal”, que en algún momento los agricultores del delta de Bengala apreciaron las lluvias y las inundaciones que estas traían. Como los ríos solían sobrepasar las orillas, el sedimento rico en arcilla y humus contenido en la capa superior se depositaba en el suelo, lo que aumentaba su fertilidad en repetidas ocasiones. Cuando hoy en día se rompe un terraplén, la fertilidad de las parcelas agrícolas se destruye durante varios años debido al depósito de arena. Es cierto que las inundaciones ahora se han vuelto significativamente menores en volumen y en frecuencia, pero ocurren más repentinamente en áreas impredecibles y son de mayor duración. A medida que los canales de drenaje se alteran o se sedimentan, la extensión del área inundada también cambia y la actividad erosiva a lo largo de la orilla del río se vuelve más predominante.

Las medidas tomadas por el Estado para el "control de inundaciones” tienen otra área oscura: la del análisis de riesgos. Cualquier medida tecnológica tiene un elemento de riesgo, el factor "qué pasa si”, que parece haber sido minimizado al justificar la elección. El grado de incertidumbre al adoptar una opción tecnológica (el factor de riesgo) sigue siendo desconocido. Tomemos, por ejemplo, la cantidad de lluvia y su temporalidad durante los cuatro meses del monzón. Los británicos instalaron algunos pluviómetros para medir la lluvia en varias partes 
del país, pero no los suficientes para eliminar la incertidumbre. Antes de hacer una inversión grande de capital - como en el caso de una represa grande-existe la necesidad de recopilar y analizar altas cantidades de información cuantitativa de un número mucho mayor de estaciones pluviométricas. En cuencas de captación más pequeñas no hay pluviómetros y, por lo tanto, no existen datos registrados sobre el comportamiento de la lluvia. En gran parte del bajo Bengala el comportamiento de la lluvia de septiembre (posiblemente el más impredecible de todos) es un factor crítico para determinar la intensidad de las inundaciones. Por lo tanto, el entendimiento sobre el cual se funda esta intervención tecnológica a gran escala es inestable. Es como una caja negra, y por lo tanto muchas suposiciones y extrapolaciones resultan siendo parte esencial del llamado proceso científico. Pero permítanme elaborar esta idea un poco más. Sabemos que en Bengala cerca del $50 \%$ de la lluvia llega en solo cuatro meses del año, sin embargo, la lluvia no es continua y viene en ráfagas. Hay fases de actividad de lluvia extremadamente intensa y, en consecuencia, hasta el $80 \%$ de la lluvia llega en el $20 \%$ del tiempo. Si hay $400 \mathrm{~mm}$ de lluvia en 24 horas, como sucedió en 1998, ¿es eso una anormalidad?, ¿o es normal?, ¿o es un evento extremo? Simplemente, no lo sabemos. Con todos nuestros medios tecnológicos, no podemos predecir con precisión cuánta lluvia caerá en septiembre sobre la meseta de Chotanagpur o el Bengala deltaico.

Una inundación es un fenómeno "no localizado", que ocurre en un área grande, con causas ampliamente extendidas en áreas muy vastas. Sin embargo, la "solución" imaginada a este problema fue localizada, por ejemplo, la construcción de una presa en un lugar específico. Por lo tanto, el control sobre esa ubicación particular da el poder para determinar el bienestar de un número mucho mayor de personas que viven aguas arriba o aguas abajo. En varios casos, si la lluvia fuera demasiado intensa y las capacidades de almacenamiento no pudieran contener esta cantidad adicional de agua en el embalse, las administraciones del proyecto se verían "obligadas" a liberar el agua en los ríos que ya están llenos. Esta acción generalmente se justifica con otro término técnico: inundación de diseño. Esto significa que el grado de protección contra inundaciones proporcionado en la solución es solo para un cierto límite de inundación. Si el agua supera el nivel especificado, no hay más remedio que dejar salir el agua y provocar inundaciones río abajo. Ante la ausencia de datos completos sobre la lluvia y otros parámetros, lo que ocurre en realidad es una negligencia frente a los riesgos involucrados en una elección tecnológica. Las medidas de control de los proyectos modernos de desarrollo fluvial que se han llevado a cabo hasta ahora con mucho entusiasmo en la India pueden describirse mejor como "tecnologías 
de buen clima"4, una especie de medida ad hoc a través de la cual podemos saber cómo el poder, la autoridad y las construcciones de "verdad" trabajan juntas para producir cierto tipo de conocimiento. Este es un conocimiento que asumió una superioridad sobre otras formas y sistemas de conocimiento de las cosas que nos importan a nosotros. En algunas partes del país, como en Bihar, los terraplenes de Kosi han creado una mayor tensión política como consecuencia de esa elección tecnológica. Cuando ocurren rupturas en algún lugar a lo largo del terraplén durante los monzones intensos, los que viven afuera insisten en que la ruptura ha sido ocasionada por quienes viven dentro del área del terraplén. ¿Los planificadores del río alguna vez visualizaron este tipo de conflictos sociales y políticos como una consecuencia de su intervención?

En la psicología popular, especialmente entre los citadinos, un "factor de miedo" opera en términos de las inundaciones. La mente urbana teme la furia de los ríos. En un país como India, donde existen amplias brechas en casi todos los aspectos de los sectores rurales y urbanos de la economía, también existe una clara brecha de percepción con respecto a los ríos y sus inundaciones. Las ciudades son el lugar donde se concentra gran parte del capital de una sociedad en desarrollo y, por lo tanto, la tarea principal del Estado es protegerlas. Por ejemplo, fue solo después de la inundación de 1943, cuando Calcuta fue separada del resto del mundo, que las inundaciones de Damodar se sometieron a un serio escrutinio por parte de la élite de la ciudad. Antes de ese evento también había comités e investigaciones, pero nunca fueron tan importantes como para necesitar la formación de un sistema completamente nuevo de control de ríos. Miembros de una familia campesina, habiendo pasado toda su vida junto a un río propenso a las inundaciones, han sabido que las aguas de las inundaciones retroceden y, cuando lo hacen, la tierra se vuelve más productiva, enriquecida con las capas superiores de estas aguas que son ricas en humus y arcilla. Más que a las inundaciones como tales, ellos les temen a los ataques de erosión inesperados de los ríos que les roban sus tierras, o a la deposición de arena en la tierra cuando las aguas de las inundaciones se precipitan a través de una brecha en los terraplenes y vuelven las tierras incultivables permanentemente. Sin embargo, la élite urbana que toma las decisiones tecnológicas no es la misma que aquellos que tienen que soportar los resultados finales de estas decisiones. Desde la independencia, el primer grupo ha considerado las inundaciones como el principal "problema" creado por los ríos. Muchas de las miserias de hoy son resultado de esta actitud y

4 En el original, "fair weather technologies", expresión que se refiere a tecnologías puntuales. [N. del T.]. 
se relacionan con la manera en que los ríos han sido problematizados en la India, en primer lugar.

La gente rural en Bengala había vivido durante generaciones armoniosamente con los estados de ánimo de la naturaleza, mediante intrincados sistemas de ajuste al ritmo a medida que los ríos subían y bajaban. Las inundaciones solían estar confinadas a las áreas vecinas de los canales desbordados y, dado que ocurrían de forma más o menos regular, fueron negociadas por la población local con precauciones nativas desarrolladas a través de la experiencia formada durante cientos de años. Dichas prácticas no usurparon ni los derechos de un río ni los derechos de manejo de los recursos de las comunidades que viven a lo largo del río. Incluso la arquitectura nativa respetó los derechos de los ríos que se extienden más allá de sus riberas durante los monzones. Las casas más antiguas en muchos pueblos a lo largo del curso bajo del Damodar tienen pisos de plintos altos para protegerlas de las inundaciones.

Démonos un gusto brevemente y viajemos más atrás, a los tiempos védicos. Los ríos allí son básicamente como seres humanos, pues cada uno tiene su género, estado de ánimo y carácter específicos. Los ríos son alabados, amados, adulados y su furia es apreciada. El río bajó para darle paso a Vishwamitra junto con su ejército y carruajes. Pero lo hizo de buena gana, "como la madre se agacha para alimentar al niño en su seno y la mujer joven para abrazar a su hombre”. En el Rigveda se dice acerca de "las aguas que son diosas"; que "aquellas que tienen el océano como su hermano mayor fluyen del mar, purificándose, nunca descansando", y fueron cerradas por Vritra y Ahis. Los ríos descienden hacia el mar como "pájaros que regresan a los nidos". Indra abrió con un rayo un camino para ellos. Dejó que las aguas corrieran libremente y encontraran los mares. Al demoler a Vritra, Indra abrió las compuertas y con su arma "vajra” liberó el flujo de Sapta Sindhu. El mundo de los humanos y el mundo de los ríos nunca estuvieron separados en esta cosmovisión. Incluso los cuentos populares no tan antiguos sobre Damodar lo ven como típicamente "no ario", el dador y el tomador, una entidad con una voluntad y un espíritu indomables. En algún lugar a lo largo del camino todo esto cambió.

Para volver al presente una vez más, notamos que a lo largo de los años el Estado ha hecho mayor hincapié en construir capital físico en los ríos en lugar de capital social entre las personas que viven en sus llanuras de inundación. El Estado ha percibido el control de los ríos como su propia responsabilidad, y como poseía todos los recursos naturales que están dentro de sus fronteras políticas, su propiedad sobre los ríos también fue anunciada a través del "entrenamiento fluvial”. Imaginar los ríos como causantes de la "amenaza de las inundaciones” 
ignora una dimensión vital de estos: son esencialmente canales de drenaje. Los ríos sirven para drenar el agua de un área amplia en el mar, no son áreas de almacenamiento. Cualquier canal que se abra para dejar pasar el exceso de agua debe tener una salida fácil hacia el mar o hacia otro canal de agua. Los canales DVC ignoran este hecho básico y drenan en una zona baja que permanece bajo el agua durante más de cinco meses al año. El valle bajo del Damodar no es una excepción, pues la congestión del drenaje se ha convertido en un problema grave en varias partes del país, un tema que raramente es asumido por el Estado.

Por lo tanto, encontramos que las grandes presas y terraplenes fueron el producto de la objetivación de los ríos, privándolos de su derecho a extenderse por el espacio y estableciendo el dominio de los humanos sobre ellos. Esta perspectiva reemplazó los puntos de vista en los que los ríos eran percibidos como seres vivos y cada uno tenía su propia y única característica. El sentido de unidad con los ríos y el apego a ellos fueron reemplazados por la sensación de que un río, al igual que un caballo salvaje, necesita ser "adiestrado", “domado” y “controlado”.

Necesitamos preguntarnos cuidadosamente por qué queremos que los ríos sigan siendo inocentes y dóciles, y qué significa para nosotros esta "inocencia". Puede significar liberarse de la destrucción, pero también el desempoderamiento de los ríos y de las comunidades locales. Necesitamos considerar cómo nos beneficiamos de esto. El temor a las inundaciones y la seguridad también pueden estar relacionados con nuestros propios temores de perder el control sobre lo que vemos como "recurso" en los ríos. El miedo es un terreno útil y fértil para el florecimiento de una gobernanza tiránica. ¿Es esto lo que queremos para el futuro?

Una característica notable es que durante los últimos cuarenta años, desde la publicación del artículo de Ram Sarup mencionado anteriormente, las percepciones, incluso de los campesinos de Bengala, han cambiado significativamente. Se ha dado una erosión gradual de la sabiduría nativa y una reproducción de la dependencia intelectual perfeccionada durante la época colonial. La inundación ya no se considera un proceso natural e inevitable. De hecho, las inundaciones feroces ya no ocurren con regularidad, al menos en las llanuras del Ganges en Bengala. Sin embargo, cuando ocurren, son de mayor magnitud, de mayor duración y se extienden por áreas mucho más grandes. Revitalizar la cultura de "vivir con las inundaciones" es extremadamente difícil y poco práctico en áreas como el valle bajo del Damodar, donde en vez de uno, los agricultores ahora se han acostumbrado a cosechar dos o tres cultivos al año. En consecuencia, a escala de la aldea también ha habido un cambio de actitud hacia los ríos. Las comunidades locales ahora "demandan" espolones, presas, barreras (y en el caso del Damodar, las cuatro presas restantes planificadas originalmente por W. L. Voorduin del 
Tennessee Valley Authority, el experto técnico del plan del valle del Damodar). Una forma económica dominante se ha establecido muy bien, y muchos agricultores del área de comando de DVC ahora se niegan a verse a sí mismos como periféricos en el proceso de desarrollo formal del país. Si la tecnología de las represas, el fertilizante de las semillas HYV (variedades de alto rendimiento) y los terraplenes son sinónimos de desarrollo convencional, entonces es muy entendible la aspiración del agricultor de obtener también una porción del pastel. A lo largo de las décadas, a las poblaciones agrarias se les ha "dado" una noción particular de desarrollo y ahora ellas quieren más de ese desarrollo. Es la forma en que los ríos se han pensado, lo que ha hecho que sea tan difícil para la gente imaginar su reemplazo.

Tomemos el arroz boro, por ejemplo. Este cultivo es en la actualidad la principal fuente de ingresos para los agricultores del bajo Damodar. La cosecha de arroz boro depende completamente del suministro de agua de riego a través de los canales DVC, que a menudo no son suficientes o confiables. ¿Por qué los agricultores optan por el agua del canal? Simplemente porque pagan cantidades insignificantes o nada por ello. Incluso el agua subterránea cuesta más que el agua de los ríos. Para preservar sus propios intereses, la gente tiene que matar el río. Sin embargo, el agua del canal no es una oferta individual. El agua viene en un paquete y ese paquete es bastante caro. Un campesino pobre vende hasta el último objeto de oro de su esposa para comprar el paquete de tecnología intensivo en capital. Todo el proceso mapea un terreno que es estructural y está gobernado por una tendencia a la globalización que les ofrece solo unas pocas opciones que son altamente restringidas. El modo tradicional de conocimiento se ha derrumbado y la agencia humana se ha reducido a una función de fuerzas económicas.

Por lo tanto, vemos que existe una confusión en varios niveles (psicológico, material y simbólico) en términos de imaginar los ríos. Las relaciones entre subjetividad, poder, autoridad, construcciones de "verdad" y la producción de conocimiento asociada a ellos se evidencian con respecto a los ríos. Los ríos son también algo que construimos y a lo que damos sentido, y esta perspectiva en la concepción de los ríos nunca puede pasarse por alto. Si bien un río es un fenómeno natural, también es una categoría construida y, por lo tanto, las imágenes varían a medida que se producen y reprocesan constantemente a lo largo del tiempo. Cuando empezamos a notar el vaivén de significados conflictivos en la fluidez generada por varios discursos, nos permitimos reflexionar sobre las contradicciones, el uso de la fuerza y las tragedias e ironías del desarrollo fluvial moderno en la India. Bajo la mirada distante y descentrada de la ciencia 
moderna, los ríos aparecían como objetos, no como un contexto dentro del cual vivimos. El río perdió su idoneidad como una metáfora que no puede ser concebida en una forma estática. Vivimos en un tiempo de cambios rápidos, incertidumbre y grandes turbulencias. El futuro parece más aterrador que nunca y el mundo en sí parece, como los ríos, peligroso y amenazado. El río, en todos los sentidos, está en el centro de este caos.

Traducido por Alejandro Camargo Profesor asistente del Departamento de Historia y Ciencias Sociales de la Universidad del Norte, Barranquilla 